\title{
NOTAS SOBRE LOS DATOS HISTÓRICOS EN LAS INSCRIPCIONES DE QUIRIGUA Y PALENQUE
}

\author{
Por Thomas J. SHAw*
}

En este artículo presento una interpretación de algunas inscripciones de Quiriguá, Guatemala y de Palenque, Chiapas, México. Las investigaciones que se han hecho sobre las inscripciones de Quiriguá se encuentran en Morley (1937-38), Thompson (1945 y 1962), Kelley (1962). Los estudios sobre las inscripciones de Palenque son tan numerosos que no podrían ser mencionados aquí, pero el trabajo de Heinrich Berlin es el más extenso. Sigo los principios establecidos por Thompson (1950) para la escritura jeroglífica y el calendario maya. Utilizo la numeración escrita de monumentos y de glifos presentados por Morley, el sistema de Thompson para transcribir glifos y la terminología empleada por Kelley para el material histórico de Quiriguá.

El grupo de glifos que ha sido identificado por Kelley como el nombre del primer gobernante de Quiriguá se transcribe 122.175: 561 (Fig. 1a.). El signo principal 561, cielo, no fue usado realmente como tal hasta que la Estela $\mathrm{F}$ fue erigida en 9.16.10.0.0. En el monumento precedente, la Estela J, el signo principal del nombre del primer gobernante es el 82 (Fig. 1b) situado en E7 y C7. Este nombre es seguido por el glifo 561 en F7a y una posible variante en D7. El signo 561 nunca sigue al nombre del primer gobernante, cuando se le utiliza como signo principal de su nombre. Probablemente para ahorrar espacio el signo principal 82 está suprimido, confiando en los prefijos 122.175 para que el nombre sea reconocido. Eso también permite que el título 561 sea expresado en forma abreviada. Otro ejemplo del nombre del primer gobernante se ve en la Estela E, oeste (Fig. 1c) donde se le utiliza como el glifo $\mathrm{G}$ de la serie lunar de la fecha 9.14.13.4.17, 12 Caban 5 Kayab, una fecha

* Traducción de Amalia Cardós de Méndez; Museo Nacional de Antropología del INAH. 
siempre asociada con él. El emplear un glifo de nombre como glifo G se encuentra también en Palenque (Fig. 1d). El infijo identificador, 583, del nombre importante 624, "escudo con aspas" (propellershield) (Thompson, 1962:242-3, núm. 19 y 40; Coe y Benson, 1966: 21; Berlin, 1968: 140) es usado como glifo G, pero sin el prefijo 74.184, como el nombre en la Estela $\mathrm{E}$ es utilizado sin el acostumbrado prefijo 122 (Thompson, 1950: Fig. 34).

Kelley (1962 : 327) ha postulado que el acontecimiento que ocurrió en la fecha 12 Caban fue el nacimiento del primer gobernante, aunque admite la carencia de evidencia fuerte para tal interpretación. Por los datos expuestos a continuación, parecería más probable que haya sido la fecha inaugural (de entronización) de este gobernante. En la Estela J, E3, el glifo 204.747b: 126, glifo "buitre", está precediendo inmediatamente a la fecha 12 Caban (Fig. 1e). Proskouriakoff (1960: 469; 1964: 190) y Berlin (1968: 144) han demostrado que el glifo "buitre" está asociado estrechamente con entronización. Después de la fecha 12 Caban, F4 a F6, están cinco glifos (Fig. 1f) formando una clásula muy similar a la que está en el escalón medio superior de la estructura 44 de Yaxchilán, desde D11 hasta C13 (Fig. 1g). La clásula en Quiriguá se transcribe: 121: 713.181: 126/IX. 714.181/122.1083?: 102/1030?/89.60: 757. La de Yaxchilán es 679a-d. 121: 713. 181/IX. 714/122: 563/1083?: 102/1030?/89.60: 757. Las pocas diferencias entre las dos cláusulas son, el cambio de posición de la mano 713, en la Estela J, debido al traslapo de una pluma de la representación situada en frente (de la inscripción); * la ausencia en Yaxchilán del postfijo 181 en el glifo 714, y en Quiriguá, la supresión del glifo 563 aún conserva el prefijo 122. Proskouriakoff (1963: 155-56) establece que en la cláusula de Yaxchilán los glifos podrían referirse a la "consolidación del poder de escudo-jaguar" después de una batalla importante. Eso permite realizar, comparativamente, una interpretación similar en Quiriguá.

Otros glifos de acontecimientos asociados con 12 Caban, o su aniversario, pueden encontrarse en la Estela D, oeste, en B17b 1.h. (Fig. 2a.) y en el zoomorfo G, panel D en $\mathrm{Z} 2$ u.h. y posiblemente en Y2 u.h. (Fig. 2b). Debido a su forma y elementos característicos se les ha identificado como glifos del "grupo de afijos" **. Proskouriakoff (1960: 469-70) ha demostrado que este conjunto de afijos normal-

* El texto inglés dice: because of an everlapping feather from the front desing". N. del E.

** "affix cluster". 
mente registra entronización cuando aparece con otros glifos, y los aniversarios, cuando está solo. En la Estela D, el grupo de afijos, forma parte de la cláusula conmemorativa de los dos katunes cumplidos después del 12 Caban. En el zoomorfo $\mathrm{G}$ se le encuentra en referencia directa a la fecha 12 Caban pero está precedido por un glifo erosionado. En el altar U de Copán, en K2, hay un conjunto de afijos precedido por el glifo 644 en referencia a 6 Caban $10 \mathrm{Mol}$, fecha de entronización en el sitio. Otro ejemplo del 644 se encuentra también en el altar U, en 04 (Fig. 2c). Berlin (1968) demostró que el glifo 644 se utilizó en ciertos sitios para registrar entronización. El glifo erosionado que precede al conjunto de afijos en el zoomorfo G tiene el mismo sufijo, 126, que tiene el glifo 644 en Copán. Si éste es el glifo 644 en Quiriguá, entonces es una referencia directa a entronización.

$\mathrm{La}$ edad del primer gobernante pudiera estar indicada por la presencia de los glifos "cinco-katún/concha-mano", (Fig. 2d) que aparecen primero en sus títulos en las Estelas A y C en 9.17.5.0.0. El uso de katunes numerados para registrar la edad de un gobernante ha sido mencionado por Proskouriakoff (1963: 153). Otra posible referencia a la edad del mismo gobernante es el glifo "concha-mano" 672 , con un coeficiente cuatro en la Estela E, este, en C12 (Fig. 2e). El glifo del katún puede estar suprimido cuando va acompañado por el glifo 672 como lo está en el zoomorfo P, sur, en C7b (Fig. 2f) y en Morales, Estela 2, D4. En la Estela E, el 672 está precedido por una forma personificada del glifo $u$ cab (Kelley, 1962: 324, Fig. 4) 204.525P: 246. Usualmente al prefijo 1 se le encuentra con los glifos $u c a b$, pero Proskouriakoff (1968) ha demostrado que el 204 es intercambiable con el prefijo 1 . Kelley señala que los glifos $u c a b$ están estrechamente asociados con los apelativos de los gobernantes. Eso añade importancia a la posibilidad de que el glifo IV: 672 se refiera al primer gobernante. Si ésta es una anotación de su edad, entonces él estaba en los últimos tunes del cuarto katún de su vida cuando la Estela $\mathrm{E}$ fue erigida en 9.17.0.0.0. En la época en que las Estelas A y C fueron erigidas, 5 tunes más tarde, él había entrado en el quinto katún de su vida. Si esta interpretación es correcta, entonces tendría que haber nacido entre 9.13.0.0.0. y 9.13.5.0.0 para encajar en las edades sugeridas por las anotaciones del katún.

Kelley (1962: 328-30) ha señalado que en el zoomorfo G probablemente se registra la muerte de alguien. En el panel D, en K'1L'1, está la fecha 11 Ik 5 Yax (9.17.14.13.2). Le siguen inmediatamente cuatro glifos y después el nombre y títulos del primer gobernante 
(Fig. 3a.). El segundo glifo después de la fecha tiene el signo principal 503, Ik. Un grupo de glifos con 503 como uno de sus signos principales y con afijos casi idénticos, ha sido discutido por Proskouriakoff (1963: 163) quien señala que sirven para registrar las muertes de ciertos individuos en Yaxchilán (Fig. 3b). Los glifos en los dinteles 27 y 28 de Yaxchilán se transcriben 1.179: 503:? Ellos siguen al glifo 575 que tiene un prefijo dudoso. El glifo en el zoomorfo G es 204.58: 503:? El siguiente glifo lleva como afijo al 575. El prefijo 1 está reemplazado por el 204, como en el glifo $u$ cab. Según dibujo de Maudslay, aparece el afijo 58, pero Thompson registra un $179 \mathrm{du}-$ doso. Ambos son muy parecidos y posiblemente sean intercambiables. La fecha $11 \mathrm{I} k$ es la última asociada directamente con el primer gobernante y está registrada por lo menos tres veces en el zoomorfo $\mathrm{G}$, indicando claramente su importancia.

Setenta y seis días después de la muerte del primer gobernante, propuesta en 9.17.14.13.2, se encuentra una fecha muy importante: 9.17.14.16.18, 9 Etznab 1 Kankin. Esta fecha está registrada en el zoomorfo G en D'4 1.h., E'4 u.h., en el altar del zoomorfo O como serie inicial, con glifos de cuerpo entero, y en el altar del zoomorfo $\mathrm{P}$ en J2 1.h. Kelley identificó el nombre del segundo gobernante quien es presentado con la fecha 9 Etznab, pero no identificó glifos de acontecimientos asociados con él. En el panel D del zoomorfo G, en F'4 u.h., E'4 1.h., y en el altar del zoomorfo O en M1 (Fig. 3c y d), ambos siguen inmediatamente a la fecha 9 Etznab; allí se puede ver la combinación a la similar 713/757 que discutió Berlin (1965). En vista de que el acontecimiento ocurrió en 9 Etznab, poco tiempo después de la muerte del primer Gobernante y que se presenta un nombre nuevo, es muy probable que la fecha se refiera a la entronización del sucesor del citado gobernante.

Esta misma interpretación puede hacerse en Palenque por la repetición de la combinación 713/757. En la vasija de barro negro con serie inicial está 713/757 en C1, D1, asociado con la última fecha conocida en Palenque, 9.18.0.4.4, 7 Kan 17 Muan (Fig. 3e). El glifo 713 está escrito algo más pequeño de lo usual y está registrado por Thompson como un sufijo del 684 , glifo "dolor de muelas", tallado arriba de él. El glifo 684 es bien conocido como un glifo de entronización (Proskouriakoff, 1960; Berlin 1968). Este es el único ejemplo conocido del glifo 684 usado como un glifo de acontecimiento en Palenque, y su conexión íntima con el 713/757 es obvia. Pudiera ser significativo que las relaciones cerámicas entre Palenque y Piedras Negras (Rands y Rands, 1957: 147-49), donde 684 fue 
usado regularmente para registrar entronización, se volvieran más fuertes durante los años postreros del periodo Clásico tardío, cuando la vasija con la serie inicial fue grabada. Otra asociación del 713/ 757 con entronización, en Palenque, puede verse en el panel del $\mathrm{Pa}-$ lacio, Ruz 1, en R5, Q6, donde sigue inmediatamente a la fecha 5 Lamat $6 \mathrm{Xul}$ (Fig. 3f). Berlin (1968) demostró que esta misma fecha se encuentra en el tablero de los 96 glifos, con el 644 y el conjunto de afijos, para registrar la entronización (Fig. $3 g$ ). El contexto en el que aparecen otros glifos $713 / 757$ no excluye su uso para indicar entronización. Aparecen por lo menos 21 veces en las inscripciones de Palenque: 10 veces en el Templo de la Cruz, dos veces en Ruz 1, en Ruz 2, en el Templo de las Inscripciones y el Templo de la Cruz Foliada y una vez en el Templo del Sol, en la escalinata jeroglífica de la Casa C y los estucos del Templo XVIII. Ellos están asociados con las importantes fechas 5 Lamat $1 \mathrm{Mol}$, tres veces, y con 8 Oc $3 \mathrm{Kayab}$, seis veces, ambas posibles fechas de entronización. La escasez de glifos de entronización identificados en Palenque hace que se requiera del uso de otros glifos, tales como los 713/757, para expresar tal evento en dicho sitio.

En resumen, tal parece que el primer gobernante de Quiriguá inició su mandato en 9.14.13.4.17, 12 Caban 5 Kayab. Era probablemente un anciano en la época en que fueron erigidos los monumentos más importantes de Quiriguá. A juzgar por las anotaciones de katún con su nombre, él pudiera haber tenido cerca de cien años cuando murió en 9.17.14.13.2. Puede verse a su sucesor tomando posesión, tal como lo expresa la combinación $713 / 757$, poco tiempo después de su muerte. El uso de los glifos 713/757 para denotar entronización también aparece en Palenque donde parece haber sido la expresión favorita. Si los datos anteriores sobre Quiriguá son correctos, entonces el primer gobernante disfrutó de una vida excepcionalmente larga y de un periodo de gobierno mayor de 60 años, siendo posiblemente el más largo del que haya constancia.

Nota: Cuando había concluido este ensayo, me enteré de otras publicaciones importantes precedentes a mi trabajo. Estas contienen algunos puntos de vista muy similares a los que yo discuto. Las mencionadas publicaciones son: "Ueber Mondseriationen beiden Maya". Bulletin of the Swiss Society of Americanists, 1970, de Heinrich Berlin; "The Hand-Grasping-Fish and Associated Glyphs", Mesoamerican Writing Systems, 1973, de Tatiana Proskouriakoff; y en la primera parte de la Primera Mesa Redonda de Palenque, "Lords of Palenque-The Glyphic Evidence", 1974, de Peter Mathews y Linda Schele.

Deseo dar las gracias a Heinrich Berlin por sus provechosas sugerencias al preparar este ensayo; así también deseo expresar mis agradecimientos 
a Ken Hedges del San Diego Musseum of Man, por haberme permitido realizar en este lugar algunos estudios de los monumentos de Quiriguá.

\section{PROCEDENCIA DE LAS ILUSTRACIONES}

Figura 1:

a - f Maudslay 1889-1902.

g Maler 1903.

Figura 2:

a - f Maudslay 1889-1902.

Figura 3:

$\begin{array}{ll}\text { a, c } & \text { Maudslay 1889-1902. } \\ \text { b } & \text { Proskouriakoff } 1963 . \\ \text { d } & \text { Thompson 1945. } \\ \text { e } & \text { Ruz 1952. } \\ \text { f } & \text { Ruz 1959. } \\ \text { g } & \text { Palacios 1937. }\end{array}$

\section{REFERENCIAS}

BERLIN, H.

1965 The Inscription of the Temple of the Cross at Palenque. American Antiquity, 30 (3): 330-42.

1968 The Tablet of the 96 Glyphs at Palenque, Chiapas, México. Middle American Research Institute, Tulane University Pub. 26, 135-49.

Coe, M. y E. P. Benson

1966 Three Maya Relief Panels at Dumbarton Oaks. Dumbarton Oaks Studies in Pre-Colombian Art and Archaeology, 2.

Kelley, D. H.

1962 Glyphic Evidence for a Dynastic Sequence at Quiriguá, Guatemala. American Antiquity, 27 (3): 323-35.

Maler, T.

1903 Researches in the Central Portion of the Usumacintla Valley. Mem. Peabody Mus. Harvard Univ., 2 (2).

Maudslay, A. P.

1889- Archaeology. Biologia Centrali-Americana.

19025 Vols. London.

Morley, S. G.

1935 Guide Book to the Ruins of Quiriguá. Carnegie Inst. Wash. Supp. Pub. 16. 
1937- The Inscriptions of Peten. Carnegie Inst. Wash. Pub. 437. 19385 Vols.

Palacios, E. J.

1937 Más Gemas del Arte Maya en Palenque. Anales del Mus. Nac. de Arqueol. Hist. y Etnog., Época 5, Vol. II: 193-225. México.

Proskouriakoff, T.

1960 Historical Implications of a Pattern of Dates at Piedras Negras, Guatemala. American Antiquity, 25 (4): 454-75.

1963 Historical Data in the inscriptions of Yaxchilan. Part. I. Estud. Cultura Maya, 3: 149-68. México.

1964 Historical Data in the Inscriptions of Yaxchilan. Part. II. Estud. Cultura Maya, 4: 177-202. México.

1968 The Jog and Jaguar Sign in Maya Writing. American Antiquity, 33 (2): 247-51.

Rands, R. L. y B. C. Rands

1957 The Ceramic Position of Palenque, Chiapas. American Antiquity, 23 (2): 140-50.

Ruz, L., A.

1952 Exploraciones en Palenque: 1950. Anales I.N.A.H., 5: 25-45. México.

1959 Palenque, Guia Oficial. I.N.A.H. México.

Thompson, J. E. S.

1945 The Inscription on the Altar of Zoomorph O, Quiriguá. Carnegie Inst. Wash., Dept. Archaeol., Notes on Middle Amer. Archaeol. and Ethnol., No. 46.

1950 Maya Hieroglyphic Writing: Introduction. Carnegie Inst. Wash. Pub. 589.

1952 La Inscripción Jeroglífica del Tablero de El Palacio, Palen. que. Anales I.N.A.H., 4: 61-68, México.

1962 A Catalog of Maya Hieroglyphs. Norman. 
ESTUDIOS DE GULTURA MAYA

D 13

E $7 \quad$ F 7 a
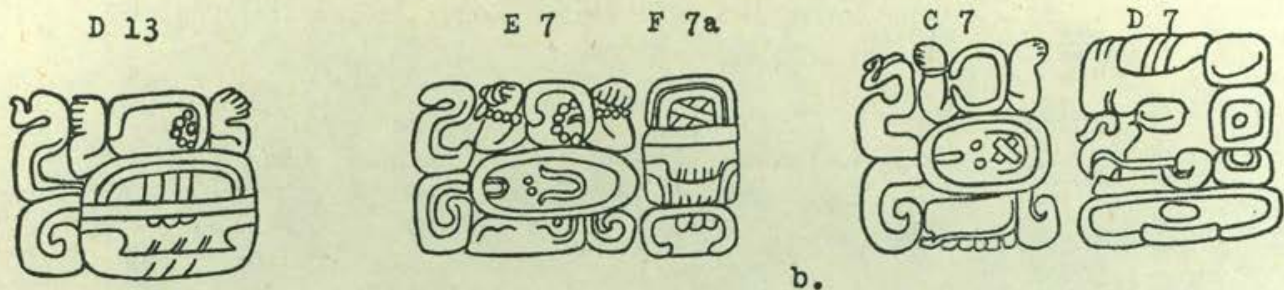

a.

b.
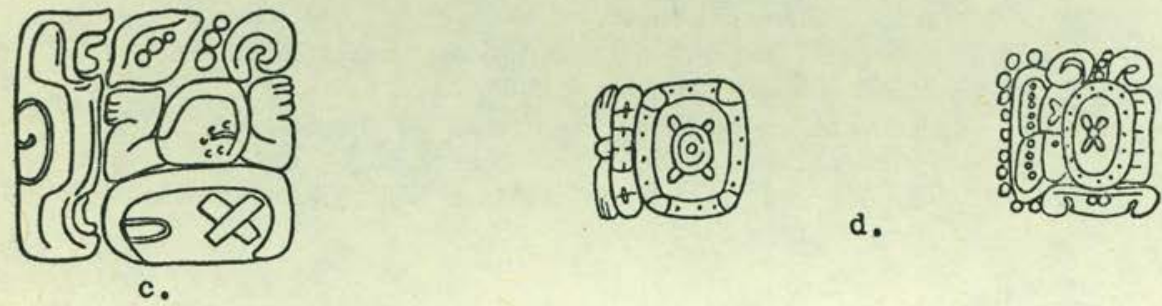

E 3

F 3

E 4

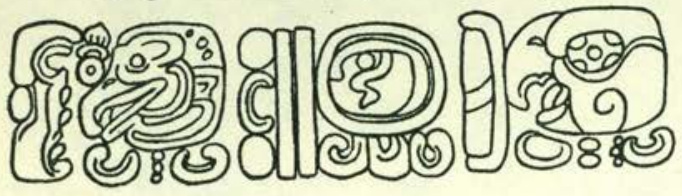

F 4

E 5

F 5

E 6

F 6

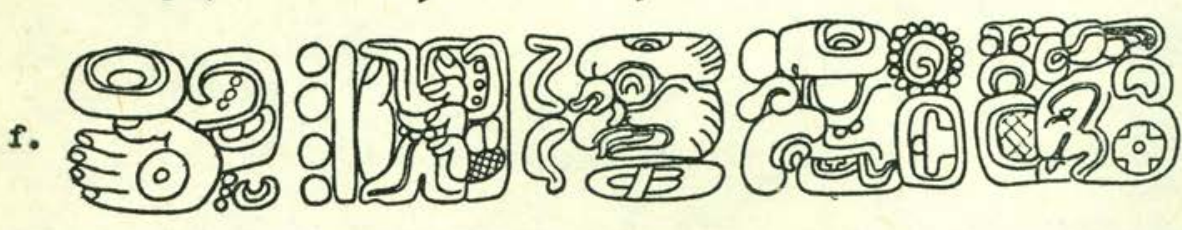

g.
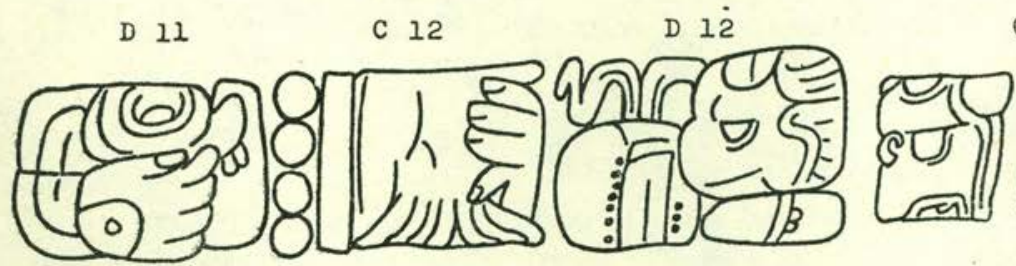

C 13

FigurA 1. Jeroglíficos. 
Y2u.h.

z2u.h.

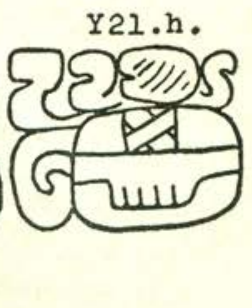

1
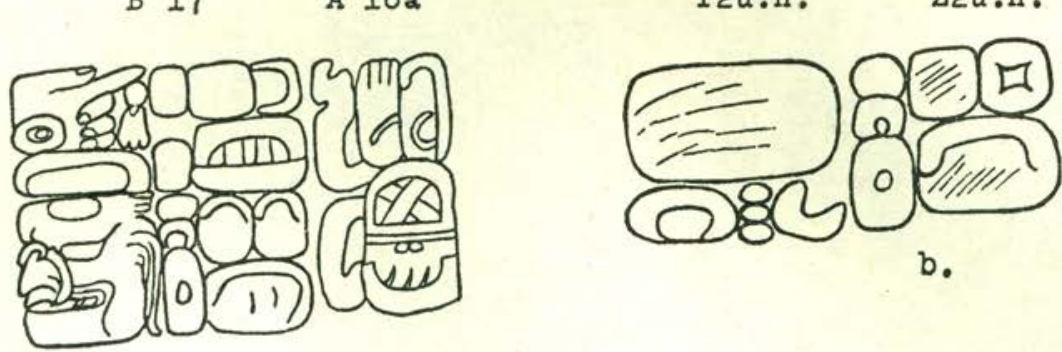

a.
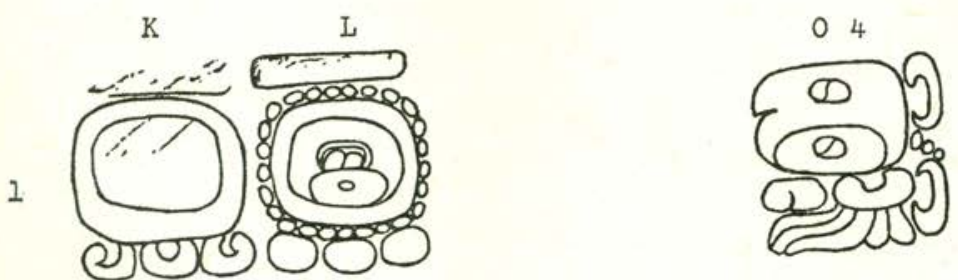

2

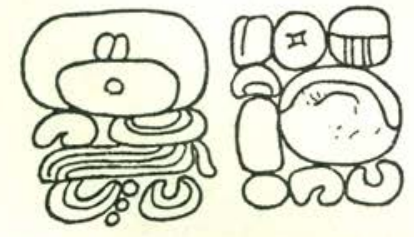

c.

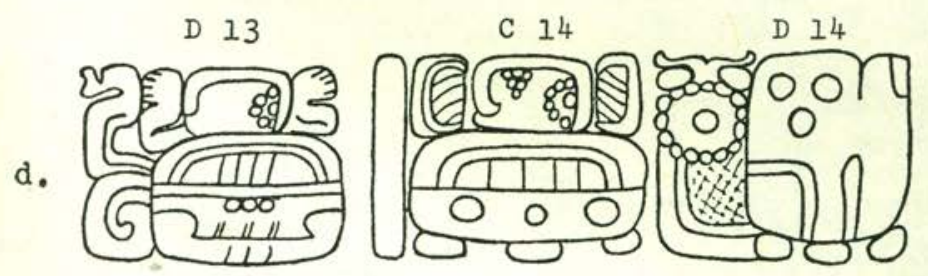

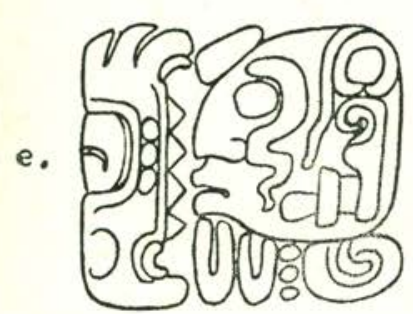

D 11

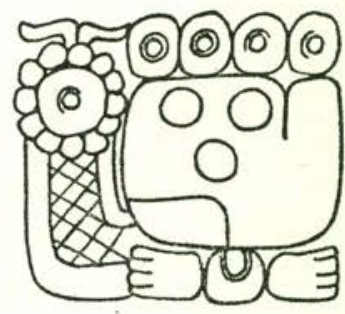

C 12

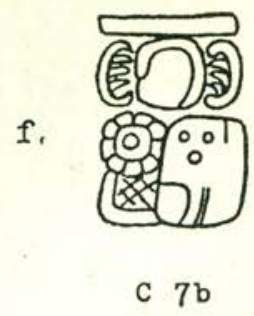

Figura 2. Jeroglíficos. 

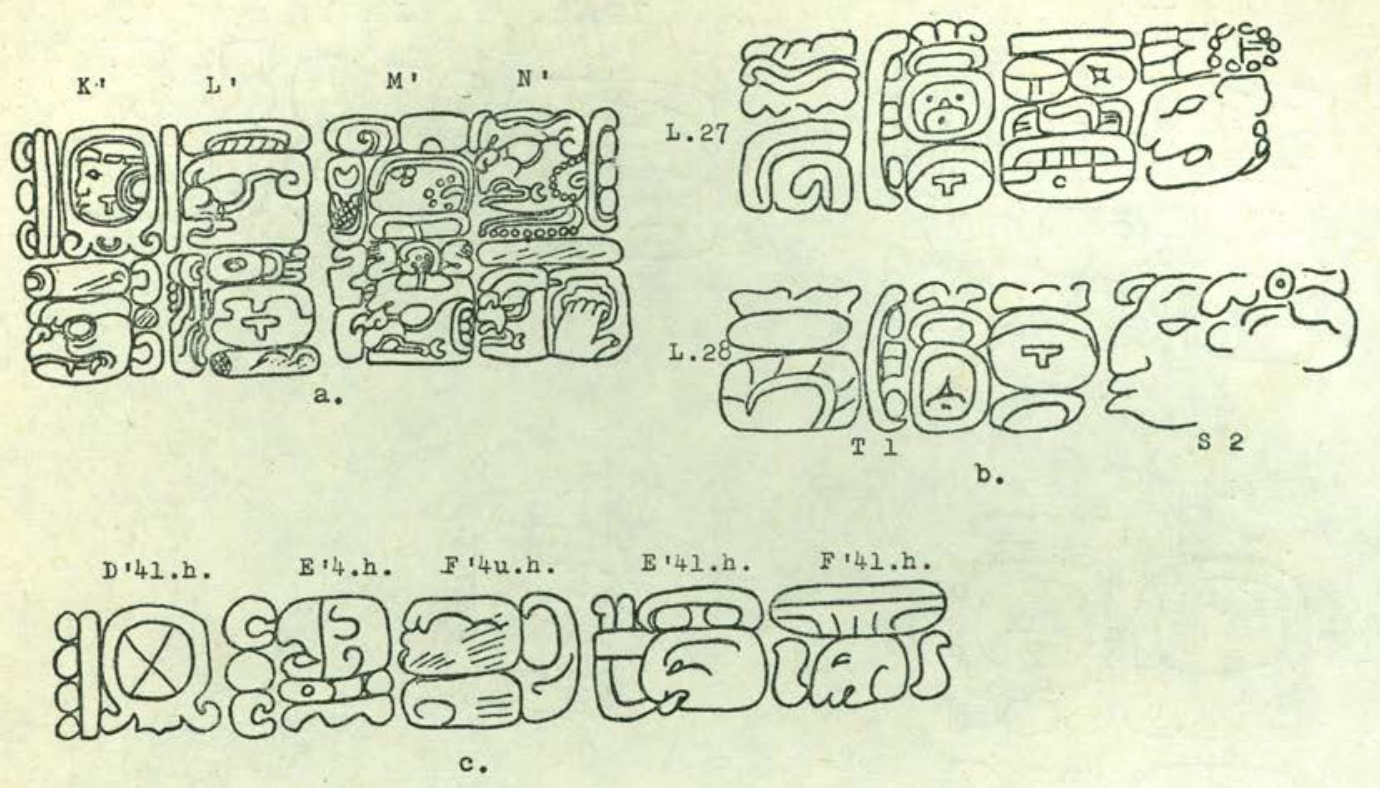

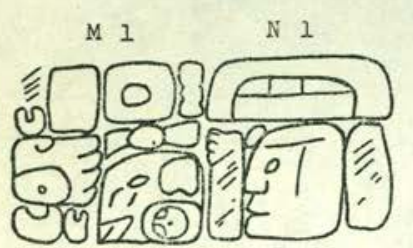

d.
C 1

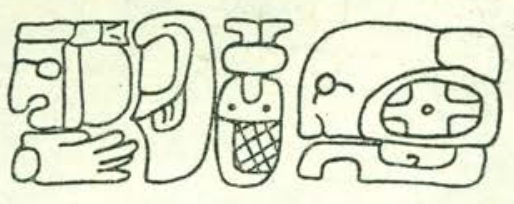

e.
R 4
Q 5
R 5
Q 6
R 6
Q 7
R 7
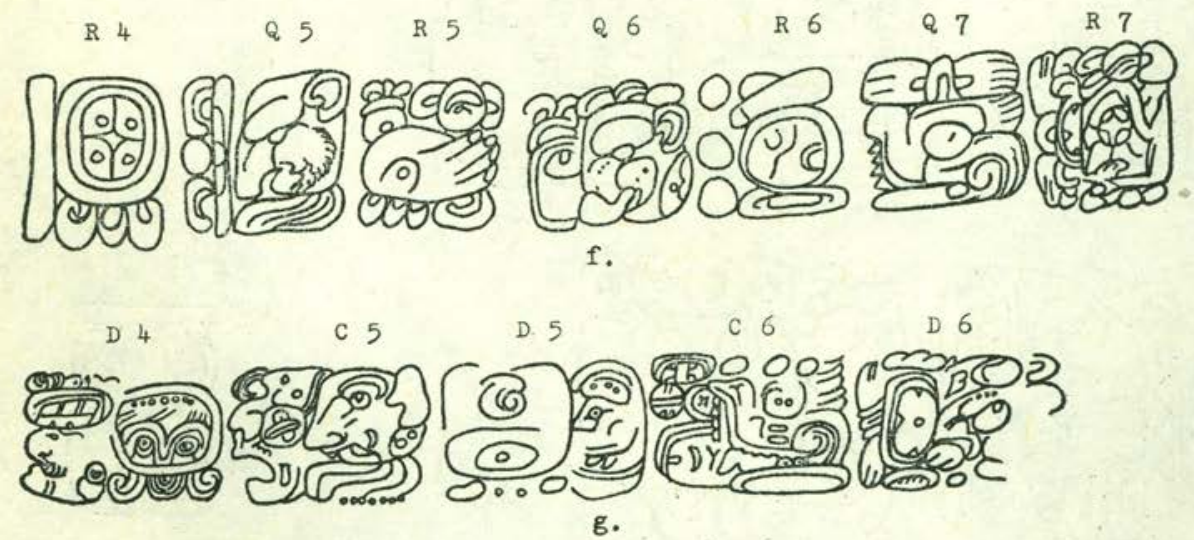

Figura 3. Jeroglíficos. 